\title{
Lag Time between Onset of First Symptom and Treatment of Retinoblastoma: An International Collaborative Study of 692 Patients from 10 Countries
}

\author{
Swathi Kaliki ${ }^{1, *(D)}$, Xunda Ji ${ }^{2}$, Yihua Zou ${ }^{2}$, Riffat Rashid ${ }^{3}$, Sadia Sultana ${ }^{3}$, Sadik Taju Sherief ${ }^{4}$ (D), \\ Nathalie Cassoux ${ }^{5}$, Rosdali Y. Diaz Coronado ${ }^{6}{ }^{\mathbb{D}}$, Juan Luis Garcia Leon ${ }^{7}$, Arturo Manuel Zapata López ${ }^{6}$, \\ Vladimir G. Polyakov ${ }^{8,9}$, Tatiana L. Ushakova ${ }^{8,9}$, Soma Rani Roy ${ }^{10}$, Alia Ahmad ${ }^{11}$ (D), Lamis A1 Harby ${ }^{12}$ (D), \\ M. Ashwin Reddy ${ }^{12,13}$ (D), Mandeep S. Sagoo ${ }^{12,13,14}\left(\mathbb{D}\right.$, Jesse L. Berry ${ }^{15}{ }^{\mathbb{D}}$, Jonathan Kim ${ }^{15}$, Ashley Polski ${ }^{15} \mathbb{D}$, \\ Nicholas J. Astbury ${ }^{16}{ }^{(}$, Covadonga Bascaran ${ }^{16}$, Sharon Blum ${ }^{17}$, Richard Bowman 16,18, Matthew J. Burton 14,16, \\ Allen Foster ${ }^{16}$, Nir Gomel ${ }^{19}$, Naama Keren-Froim ${ }^{17}$, Shiran Madgar ${ }^{17}$, Andrew W. Stacey ${ }^{20}$ (D), \\ David M. Steinberg ${ }^{21}$ (D), Ashik Mohamed ${ }^{22}$ (D), Marcia Zondervan ${ }^{16}$ and Ido Didi Fabian ${ }^{16,17}$ (D)
}

check for

updates

Citation: Kaliki, S.; Ji, X.; Zou, Y.;

Rashid, R.; Sultana, S.; Taju Sherief, S.; Cassoux, N.; Y. Diaz Coronado, R.; Luis Garcia Leon, J.; López, A.M.Z.; et al. Lag Time between Onset of First Symptom and Treatment of

Retinoblastoma: An International Collaborative Study of 692 Patients from 10 Countries. Cancers 2021, 13, 1956. https://doi.org/10.3390/ cancers13081956

Academic Editors: Jaume Mora and Samuel C. Mok

Received: 15 February 2021

Accepted: 14 April 2021

Published: 19 April 2021

Publisher's Note: MDPI stays neutral with regard to jurisdictional claims in published maps and institutional affiliations.

Copyright: (c) 2021 by the authors. Licensee MDPI, Basel, Switzerland. This article is an open access article distributed under the terms and conditions of the Creative Commons Attribution (CC BY) license (https:// creativecommons.org/licenses/by/ $4.0 /)$.
1 The Operation Eyesight Universal Institute for Eye Cancer, L V Prasad Eye Institute, Hyderabad 500034, India

2 Department of Ophthalmology, Xinhua Hospital, Shanghai Jiao Tong University School of Medicine, Shanghai 200025, China; jixunda@xinhuamed.com.cn (X.J.); 3147119084@situ.edu.cn (Y.Z.)

3 Department of Oculoplasty and Ocular Oncology, Ispahani Islamia Eye Institute and Hospital, Dhaka 1215, Bangladesh; riffat.rashid@islamia.org.bd (R.R.); sadia.sultana@islamia.org.bd (S.S.)

4 Department of Ophthalmology, School of Medicine, Addis Ababa University, Addis Ababa 3614, Ethiopia; sadik.taju@aau.edu.et

5 Institut Curie, Université de Paris Medicine Paris V Descartes, 75248 Paris, France; nathalie.cassoux@curie.fr

6 Instituto Nacional de Enfermedades Neoplasicas, Lima 15038, Peru; rosdali.diaz.c@upch.pe (R.Y.D.C.); zapatalopezarturo@gmail.com (A.M.Z.L.)

7 Anglo American Clinic, Lima 15073, Peru; jgarcia@inen.sld.pe

8 Head and Neck Tumors Department, SRI of Pediatric Oncology and Hematology, N.N. Blokhin National Medical Research Center, Oncology of Russian Federation, 115478 Moscow, Russia; vgp-04@mail.ru (V.G.P.); ushtat07@mail.ru (T.L.U.)

9 Medical Academy of Postgraduate Education, 125445 Moscow, Russia

10 Chittagong Eye Infirmary \& Training Complex, Chittagong 4202, Bangladesh; dr.somaroyceitc@mail.com

11 The Children' Hospital \& the Institute of Child Health, Lahore 54000, Pakistan; alia.ahmad@stjude.org

12 The Royal London Hospital, Barts Health NHS Trust, London E1 1BB, UK; lamis.alharby1@nhs.net (L.A.H.); ashwin.reddy4@nhs.net (M.A.R.); m.sagoo@ucl.ac.uk (M.S.S.)

13 Moorfields Eye Hospital NHS Foundation Trust, London EC1V 2PD, UK

14 UCL Institute of Ophthalmology, London EC1V 2PD, UK; matthew.burton@lshtm.ac.uk

15 Children's Hospital Los Angeles \& USC Roski Eye Institute, Keck School of Medicine, University of Southern California, Los Angeles, CA 90027, USA; jesse.berry@med.usc.edu (J.L.B.); jonkim@chla.usc.edu (J.K.); ashley.polski@usc.edu (A.P.)

16 International Centre for Eye Health London School of Hygiene \& Tropical Medicine, London WC1E 7HT, UK; nick.astbury@lshtm.ac.uk (N.J.A.); covadonga.bascaran@lshtm.ac.uk (C.B.);

richard.bowman@lshtm.ac.uk (R.B.); allen.foster@lshtm.ac.uk (A.F.); marcia.zondervan@lshtm.ac.uk (M.Z.); idofabia@post.tau.ac.il (I.D.F.)

17 Goldschleger Eye Institute, Sheba Medical Center, Tel Hashomer, Tel-Aviv University, Tel-Aviv 52621, Israel; sharonblum@tlvmc.gov.il (S.B.); shiran.madgar@sheba.gov.il (S.M.); naama.keren@sheba.health.gov.il (N.K.-F.)

18 Ophthalmology Department, Great Ormond Street Children's Hospital, London WC1N 3JH, UK

19 Division of Ophthalmology, Tel Aviv Sourasky Medical Center, Sackler Faculty of Medicine, Tel-Aviv University, Tel-Aviv 39040, Israel; nirgom@tlvmc.gov.il

20 Department of Ophthalmology, University of Washington, Seattle, WA 98195, USA; awstacey@uw.edu

21 Department of Statistics and Operations Research, School of Mathematical Sciences, Raymond and Beverly Sackler Faculty of Exact Sciences, Tel Aviv University, Tel Aviv 69978, Israel; dms@tauex.tau.ac.il

22 Ophthalmic Biophysics, L V Prasad Eye Institute, Hyderabad 500034, India; ashikmohamed@lvpei.org

* Correspondence: kalikiswathi@yahoo.com; Tel.: +91-40-68102502; Fax: +91-40-23548339

Simple Summary: The authors aimed to determine the lag time between onset of symptoms and diagnosis of retinoblastoma in countries based on their national-income and analyse its effect on the outcomes. Based on analysis of 692 retinoblastoma patients from 11 treatment centres in 10 countries, there was a statistically significant difference in the lag time between onset of symptoms and diagnosis 
of retinoblastoma based on country income level. This difference in the lag time between different countries results in varied outcomes across patients. Shorter lag time results in better chances of eye and patient survival.

Abstract: Background: The relationship between lag time and outcomes in retinoblastoma (RB) is unclear. In this study, we aimed to study the effect of lag time between onset of symptoms and diagnosis of retinoblastoma (RB) in countries based on their national-income and analyse its effect on the outcomes. Methods: We performed a prospective study of 692 patients from $11 \mathrm{RB}$ centres in 10 countries from 1 January 2019 to 31 December 2019. Results: The following factors were significantly different among different countries based on national-income level: age at diagnosis of $\mathrm{RB}(p=0.001)$, distance from home to nearest primary healthcare centre $(p=0.03)$ and mean lag time between detection of first symptom to visit to RB treatment centre $(p=0.0007)$. After adjusting for country income, increased lag time between onset of symptoms and diagnosis of RB was associated with higher chances of an advanced tumour at presentation $(p<0.001)$, higher chances of high-risk histopathology features $(p=0.003)$, regional lymph node metastasis $(p<0.001)$, systemic metastasis $(p<0.001)$ and death $(p<0.001)$. Conclusions: There is a significant difference in the lag time between onset of signs and symptoms and referral to an RB treatment centre among countries based on national income resulting in significant differences in the presenting features and clinical outcomes.

Keywords: eye; tumour; retinoblastoma; lag time; national income level

\section{Introduction}

Retinoblastoma (RB) is the most common intraocular malignancy in children worldwide. The global incidence of RB is estimated at 1 in 15,000 to 20,000 live births [1-5]. The age-standardised incidence rate of RB for children aged 0-5 years in most developed countries is $3-5$ cases per million population, while, in developing and underdeveloped countries, the incidence rate is reported to be higher at 6-10 cases per million population [6-9]. There is a vast difference in the mortality rate between continents, with $70 \%$ mortality rate in Africa, 39\% in Asia and 3-5\% in Northern America and Europe [5]. This difference in the death rates due to RB is mainly attributed to delayed diagnosis. One likely factor contributing to delay in diagnosis is increased lag time between onset of symptoms and treatment of RB.

The cause of increased lag time between onset of symptoms and treatment of RB could be multifactorial, related to social, cultural, financial, parental and healthcare associated factors [10]. Studies from various countries have highlighted the importance of early diagnosis of RB and the implications of delayed treatment. Studies from Asia have shown that a delayed diagnosis of $\mathrm{RB}$ results in an advanced disease at presentation with poorer chances of globe salvage [11,12]; studies from the United Kingdom and India have revealed higher chances of high-risk histopathological features with subsequent need for adjuvant chemotherapy $[13,14]$; a study from Brazil has shown increased mortality due to increased lag time [15]; a study from Switzerland has shown that reduced lag time is associated with early stage of the disease at presentation [16]; and a study from the Netherlands has shown correlation between early diagnosis and decreased mortality and blindness [17]. Herein, we prospectively studied the lag time between onset of symptoms and diagnosis of RB in 10 countries on five continents from 1 January 2019 to 31 December 2019 and compared the results based on country income levels to assess the causes of increased lag time and its effect on the patient outcomes.

\section{Results}

In total, 692 patients were included from 10 countries, including 74 (11\%) from a lowincome country (LIC) (Ethiopia), 294 (42\%) from lower middle-income countries (LMIC) (Bangladesh, India and Pakistan), 254 (37\%) from upper middle-income countries (UMIC) 
(China, Peru and Russia) and 70 (10\%) from high-income countries (HIC) (France, UK and USA) [18]. Of the 692 patients, 369 (53\%) were males and 323 (47\%) were females. The mean age at diagnosis of RB was 24 months (median, 21 months; range, $<1$ to 140 months) (Figure 1).

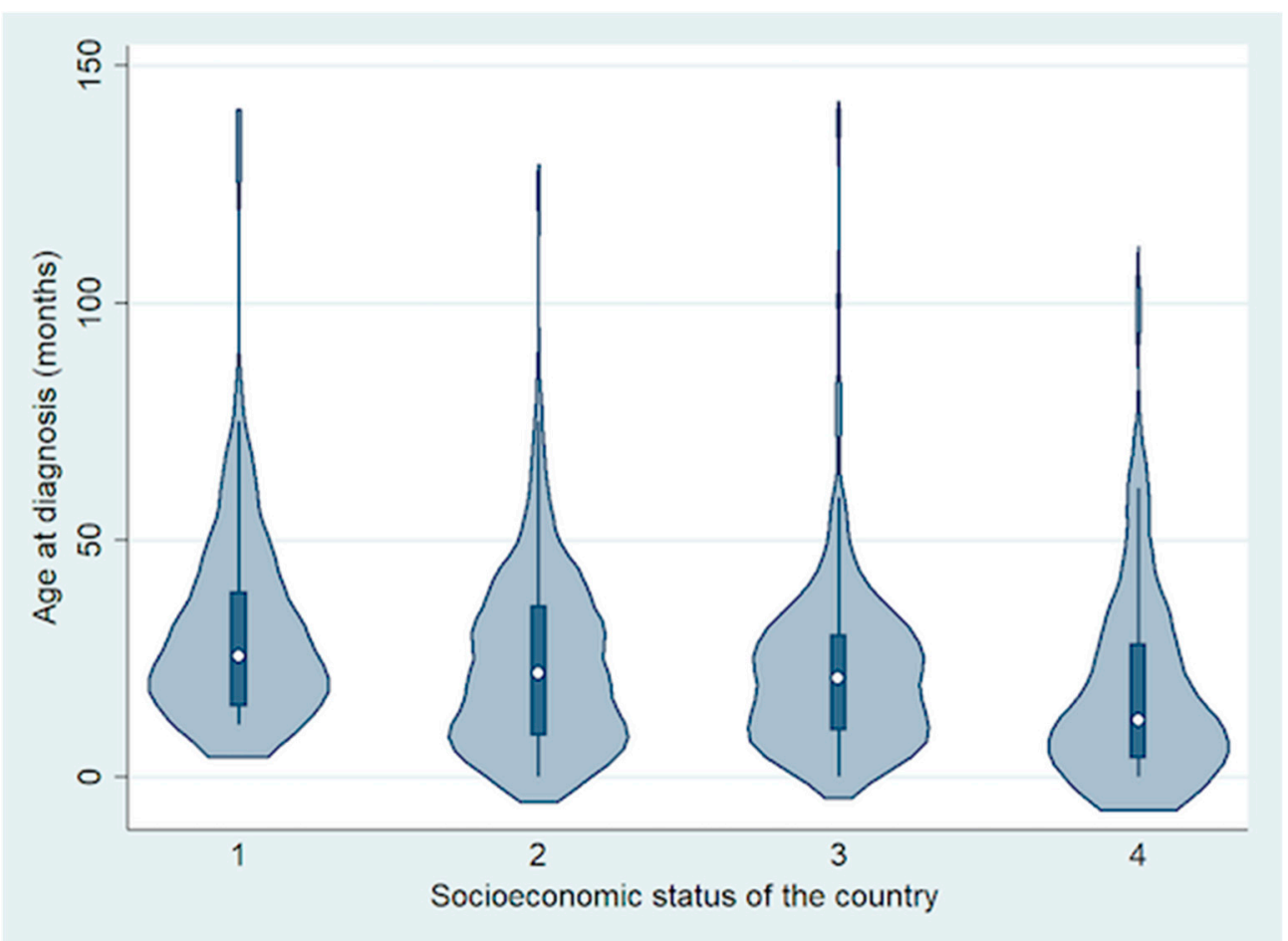

Figure 1. Violin plot showing the difference in age at diagnosis based on socioeconomic status of the country.

The most common symptom of RB was leukocoria $(n=508,73 \%)$ followed by strabismus $(n=126 ; 18 \%)$. The symptoms were most commonly detected by parents $(n=545$, $79 \%)$ followed by other family members $(n=78 ; 11 \%)$. Overall, the mean number of primary healthcare professionals (PHPs) involved before referral to RB treatment centre was 1 (median, 1; range, 0-4), including 2 (1, 1-3) for LIC, $2(1,0-4)$ for LMIC, 1 (1, 0-4) for UMIC and 1 (1, 0-3) for HIC. Of the 692 children, 396 (57\%) were diagnosed as RB after the first visit to the primary healthcare professional, 169 (24\%) were diagnosed during the second visit to the same or a different primary healthcare professional, $49(7 \%)$ during the third visit and 14 (2\%) during the fourth visit, and they were referred to an RB treatment centre for appropriate treatment. The remaining $64(9 \%)$ patients were diagnosed with RB at the RB treatment centre directly. There was family history of RB in three children (one from HIC and two from LMIC), and they were detected to have RB after routine fundus screening. Overall, the mean distance (miles) from home to RB treatment centre was 365 (median, 195; range, 2-9757) (Figure 2).

The mean lag time between detection of first symptom to visit to RB treatment centre was 150 days (median, 69 days; range, 0-1128 days) (Table 1 and Figure 3). Based on analysis by country income level, the mean lag time decreased with increasing national income level. It was 303 days for LIC (median, 251 days; range, 33-846 days), 180 days for LMIC (median, 86 days; range, 0-1128 days), 92 days for UMIC (median, 37 days; range, 1-697 days) and 56 days for HIC (median, 18 days; range, 0-366 days) (difference between groups; $p=0.0007)$. 


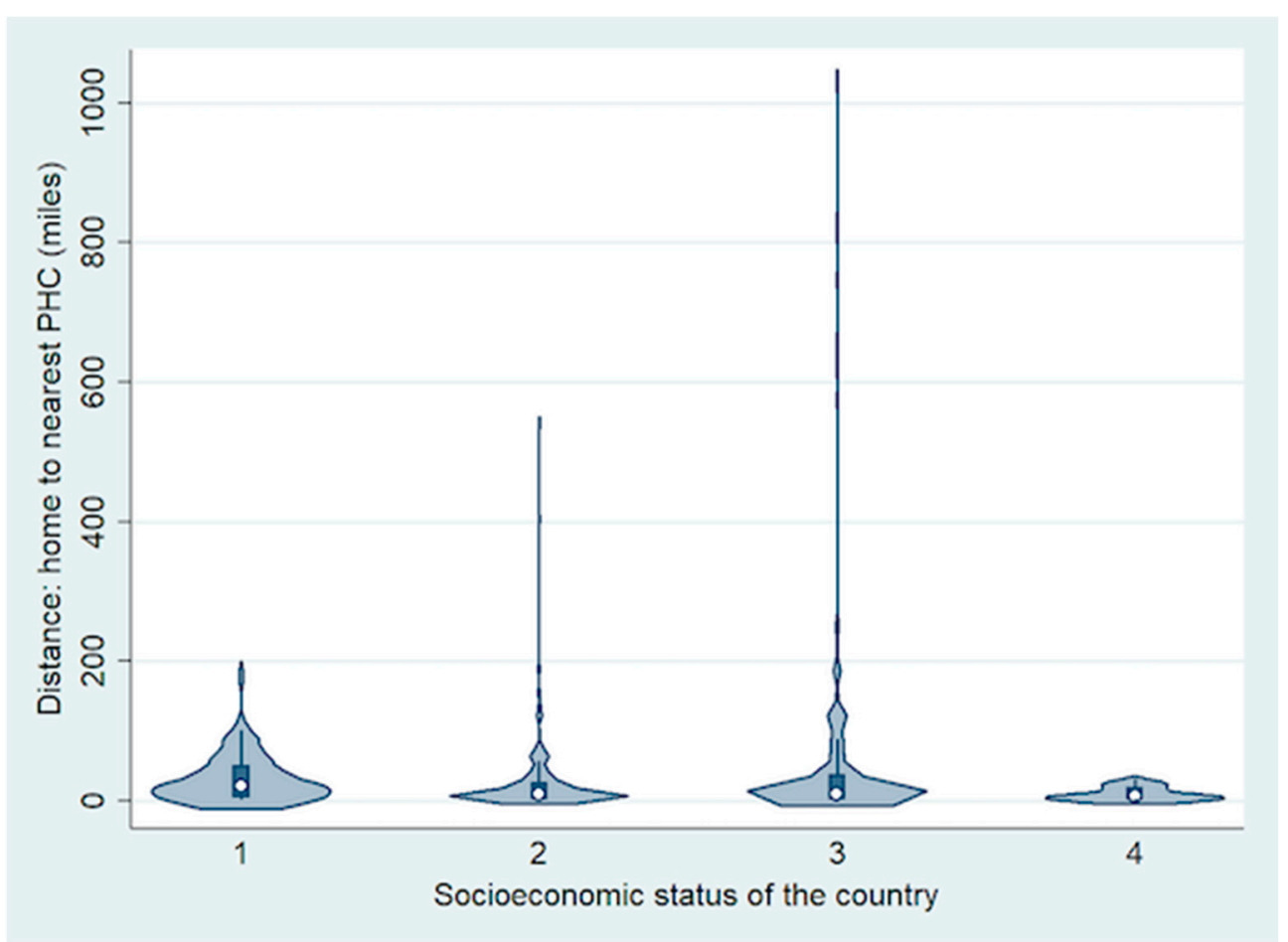

Figure 2. Violin plot showing the difference in distance from home to the nearest primary healthcare centre (PHC) based on socioeconomic status of the country.

Table 1. Demographics and presenting features of 692 retinoblastoma patients from 10 countries.

\begin{tabular}{|c|c|c|c|c|c|c|}
\hline Feature & All Cases $n=692$ & $\begin{array}{c}\text { Low-Income } \\
\text { Country (LIC) } \\
n=74\end{array}$ & $\begin{array}{c}\text { Lower } \\
\text { Middle-Income } \\
\text { Countries (LMIC) } \\
n=294\end{array}$ & $\begin{array}{c}\text { Upper } \\
\text { Middle-Income } \\
\text { Countries (UMIC) } \\
n=254\end{array}$ & $\begin{array}{c}\text { High Income } \\
\text { Countries (HIC) } \\
n=70\end{array}$ & $p$-Value \\
\hline $\begin{array}{l}\text { Age at diagnosis (months) } \\
\text { Mean (median, range) }\end{array}$ & $24(21,<1$ to 140$)$ & $31(26,11-136)$ & $24(23,<1$ to 125$)$ & $22(21,<1$ to 140$)$ & $21(15,<1$ to 106$)$ & $0.001^{\mathrm{a}}$ \\
\hline $\begin{array}{c}\text { Sex } \\
\text { Male } \\
\text { Female }\end{array}$ & $\begin{array}{l}369(53) \\
323(47)\end{array}$ & $\begin{array}{l}41(55) \\
33(45)\end{array}$ & $\begin{array}{l}154(52) \\
140(48)\end{array}$ & $\begin{array}{l}135(53) \\
119(47)\end{array}$ & $\begin{array}{l}39(56) \\
31(44)\end{array}$ & 0.94 \\
\hline $\begin{array}{c}\text { Distance from home to } \\
\text { nearest primary healthcare } \\
\text { centre (miles) } \\
\text { Mean (median, range) }\end{array}$ & $34(10,<1$ to 1040$)$ & $34(22,1-187)$ & $24(10,<1$ to 546$)$ & $47(10,<1$ to 1040$)$ & $10(6,<1$ to 31$)$ & $0.03^{b}$ \\
\hline $\begin{array}{l}\text { Distance from home to } \\
\text { retinoblastoma centre (miles) } \\
\text { Mean (median, range) }\end{array}$ & $365(195,2-9757)$ & $244(227,2-932)$ & $254(130,2-1774)$ & $527(424,2-4922)$ & $372(98,2-9757)$ & 0.25 \\
\hline $\begin{array}{l}\text { First symptom * } \\
\text { Leukocoria } \\
\text { Strabismus } \\
\text { Others }{ }^{*}\end{array}$ & $\begin{array}{l}508(73) \\
126(18) \\
100(14)\end{array}$ & $\begin{array}{l}70(95) \\
5(7) \\
4(5)\end{array}$ & $\begin{array}{l}235(80) \\
53(18) \\
31(11)\end{array}$ & $\begin{array}{l}168(66) \\
52(20) \\
44(17)\end{array}$ & $\begin{array}{l}35(50) \\
16(23) \\
21(30)\end{array}$ & $\begin{array}{r}0.09 \\
0.09 \\
0.002^{\mathrm{c}}\end{array}$ \\
\hline $\begin{array}{c}\text { First symptom noticed by } \\
\text { Parents } \\
\text { Other family members } \\
\text { Others }\end{array}$ & $\begin{array}{l}545(79) \\
78(11) \\
69(10)\end{array}$ & $\begin{array}{l}71(96) \\
1(1) \\
2(3)\end{array}$ & $\begin{array}{l}234(80) \\
41(14) \\
19(6)\end{array}$ & $\begin{array}{l}193(76) \\
34(13) \\
27(11)\end{array}$ & $\begin{aligned} 47 & (67) \\
2 & (3) \\
21 & (30)\end{aligned}$ & $\begin{array}{c}0.01^{\mathrm{d}} \\
0.47 \\
<0.0001^{\mathrm{e}}\end{array}$ \\
\hline $\begin{array}{l}\text { Number of visits to primary } \\
\text { healthcare centres before } \\
\text { referral to RB centre } \\
\text { Mean (median, range) }\end{array}$ & $1(1,0-4)$ & $2(1,1-3)$ & $2(1,0-4)$ & $1(1,0-4)$ & $1(1,0-3)$ & 0.44 \\
\hline $\begin{array}{l}\text { Lag time between first } \\
\text { symptom and visit to RB } \\
\text { centre (days) } \\
\text { Mean (median, range) }\end{array}$ & $150(69,0-1128)$ & $303(251,33-846)$ & $180(86,0-1128)$ & $92(37,1-697)$ & $56(18,0-366)$ & $0.0007^{\mathrm{f}}$ \\
\hline
\end{tabular}

$\mathrm{RB}$, retinoblastoma; * Total is $>100 \%$ since few patients had more than one symptom; ${ }^{*}$ other symptoms included low vision, red eye, watering, iris heterochromia, proptosis and eyelid swelling. ${ }^{a}$ LIC vs. UMIC ( $\left.p=0.008\right)$; LIC vs. HIC ( $\left.p=0.002\right)$. ${ }^{\mathrm{b}}$ LMIC vs. UMIC $(p=0.008) .{ }^{c}$ HIC vs. LIC $(p=0.001)$; HIC vs. LMIC $(p=0.001) .{ }^{\mathrm{d}}$ LMIC vs. HIC $(p=0.007)$. ${ }^{\mathrm{e}} \mathrm{HIC}$ vs. LIC $(p<0.001) ; \mathrm{HIC}$ vs. LMIC $(p<0.001)$; HIC vs. UMIC $(p<0.001)$. ${ }^{\mathrm{f}} \mathrm{LIC}$ vs. UMIC $(p=0.007)$; LIC vs. HIC $(p<0.001)$; LMIC vs. HIC ( $\left.p=0.002\right)$. 


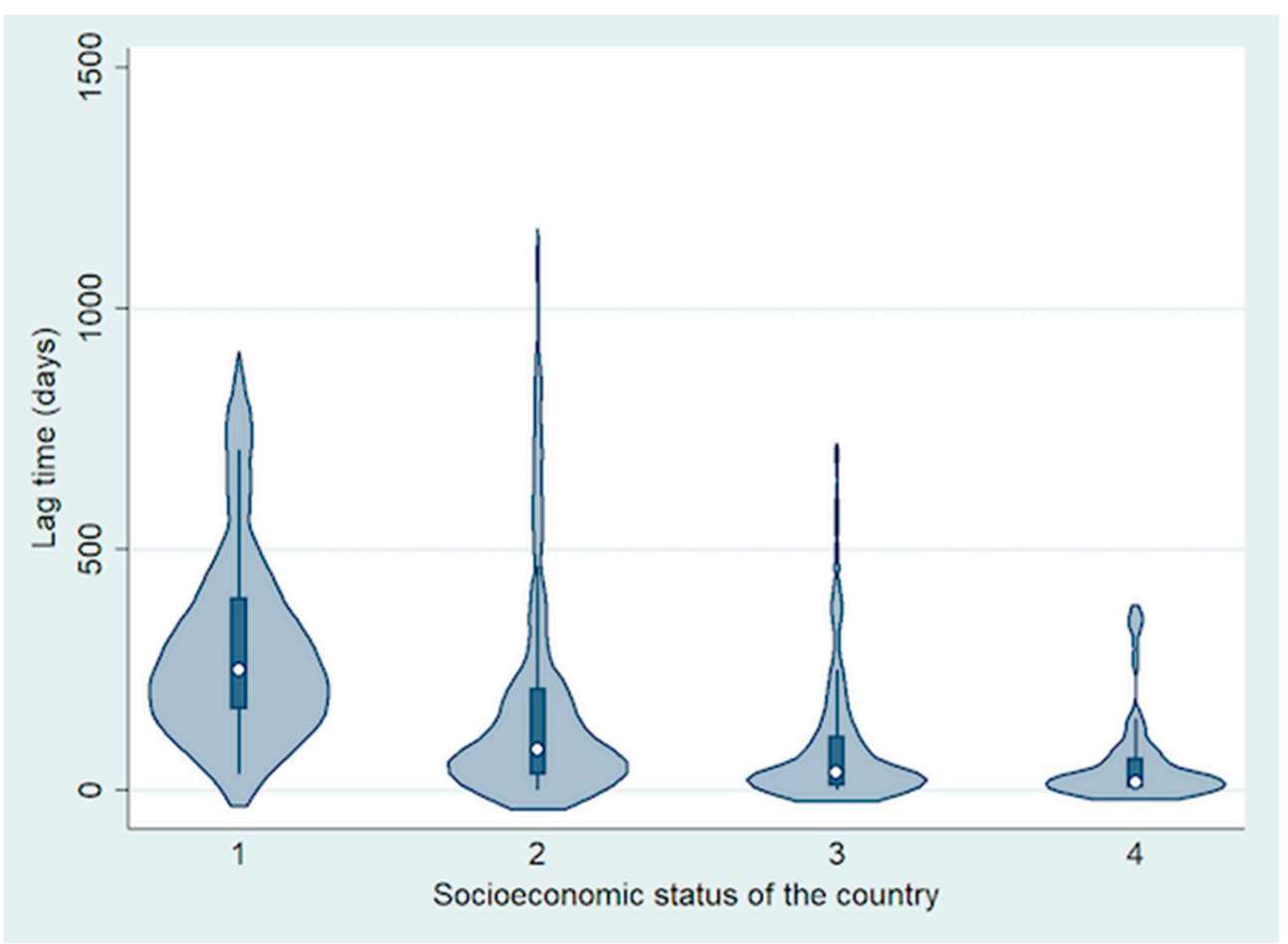

Figure 3. Violin plot showing the difference in lag time from first symptom to treatment based on socioeconomic status of the country.

The tumour was unilateral at initial presentation in $490(71 \%)$ patients and bilateral in 202 (29\%) patients. Of 894 eyes with RB, the tumour was intraocular in 815 (91\%) eyes and was associated with extraocular tumour extension in 79 (9\%) eyes. Based on AJCC classification [19], the tumour was classified as cT1 in $124(14 \%)$, cT2 in 397 (44\%), cT3 in 294 (33\%) and cT4 in 79 (9\%) eyes. Advanced RB (AJCC cT4) was noted in $20(20 \%)$ eyes from LIC, 36 (9\%) from LMIC, 23 (7\%) from UMIC and $0(0 \%)$ from HIC ( $p=0.0004)$.

Of the 866 eyes treated for RB, globe salvage was achieved in $513(59 \%)$ eyes during the study period, including 27 (30\%) eyes in LIC, 229 (58\%) eyes in LMIC, 197 (62\%) eyes in UMIC and $58(68 \%)$ eyes in HIC ( $p<0.0001)$. Of 353 enucleated eyes, histopathologic high-risk RB features were noted in 179 (51\%) eyes, including 40 (63\%) eyes in LIC, 75 (46\%) eyes in LMIC, 61 (50\%) eyes in UMIC and $3(11 \%)$ eyes in HIC. Spread to regional lymph nodes was noted in 20 (3\%) patients, systemic metastasis (including central nervous system) in $38(5 \%)$ patients and death occurred in $21(3 \%)$ patients by the conclusion of the study (Table 2).

On a multivariate analysis, the factors significantly associated with increased lag time between onset of symptoms and diagnosis of RB included lower-national income level $(p<0.001)$, increased number of visits to primary healthcare centres $(p<0.001)$, increased distance from home to RB treatment centre $(p=0.02)$, strabismus as the first symptom of RB ( $p=0.001)$ and increasing age at diagnosis $(p<0.001)$. An increase in the level of country income decreased the lag time by 75 days; every 33 miles increase in the distance from home to RB centre increased the lag time by 1 day; every extra visit to a healthcare centre increased the lag time by 36 days; the presence of strabismus as the first symptom of RB increased the lag time by 57 days; and an increase in age of diagnosis by one month increased the lag time by 3 days (Table 3). 
Table 2. Clinical features, treatment and outcomes of 692 retinoblastoma patients from 10 countries.

\begin{tabular}{|c|c|c|c|c|c|c|}
\hline Feature & $\begin{array}{c}\text { All Cases } \\
n=894 \text { Eyes in } \\
692 \text { Patients }\end{array}$ & $\begin{array}{l}\text { Low-Income } \\
\text { Country (LIC) } \\
n=98 \text { Eyes of } \\
74 \text { Patients }\end{array}$ & $\begin{array}{l}\text { Lower Middle- } \\
\text { Income } \\
\text { Countries } \\
\text { (LMIC) } \\
n=392 \text { Eyes of } \\
294 \text { Patients }\end{array}$ & $\begin{array}{c}\text { Upper Middle- } \\
\text { Income } \\
\text { Countries } \\
\text { (UMIC) } \\
n=319 \text { Eyes of } \\
254 \text { Patients }\end{array}$ & $\begin{array}{l}\text { High Income } \\
\text { Countries } \\
\text { (HIC) } \\
n=85 \text { Eyes of } \\
70 \text { Patients }\end{array}$ & $p$-Value \\
\hline \multicolumn{7}{|l|}{ Tumour laterality } \\
\hline Unilateral & $490(71)$ & $50(68)$ & $196(67)$ & $189(74)$ & $55(79)$ & 0.09 \\
\hline Bilateral & $202(29)$ & $24(32)$ & $98(33)$ & $65(26)$ & $15(21)$ & \\
\hline \multicolumn{7}{|l|}{ 8th edition AJCC } \\
\hline \multicolumn{7}{|l|}{ Tumour } \\
\hline $\mathrm{T} 1$ & $124(14)$ & $20(20)$ & $43(11)$ & $41(13)$ & $20(24)$ & $0.006^{\mathrm{b}}$ \\
\hline $\mathrm{T} 2$ & $397(44)$ & $33(34)$ & 144 (37) & $175(55)$ & $45(53)$ & 0.23 \\
\hline T3 & $294(33)$ & $25(26)$ & $169(43)$ & $80(25)$ & $20(24)$ & 0.53 \\
\hline $\mathrm{T} 4$ & $79(9)$ & $20(20)$ & $36(9)$ & $23(7)$ & $0(0)$ & $0.0004^{\mathrm{c}}$ \\
\hline \multicolumn{7}{|l|}{ Lymph nodes } \\
\hline No & $672(97)$ & $60(81)$ & $289(98)$ & $253(99)$ & $70(100)$ & $<0.0001^{a}$ \\
\hline N1 & $20(3)$ & $14(19)$ & $5(2)$ & $1(<1)$ & $0(0)$ & \\
\hline \multicolumn{7}{|l|}{ Metastasis } \\
\hline M0 & $654(95)$ & $62(84)$ & $274(93)$ & $248(98)$ & $70(100)$ & 0.13 \\
\hline M1 & $38(5)$ & $12(16)$ & $20(7)$ & $6(2)$ & $0(0)$ & \\
\hline \multicolumn{7}{|l|}{ Primary treatment * } \\
\hline Focal treatment $* *$ & $132(15)$ & $20(20)$ & $35(9)$ & $55(17)$ & $22(26)$ & 0.27 \\
\hline IVC & $381(43)$ & $18(18)$ & $204(52)$ & $131(41)$ & $28(33)$ & 0.51 \\
\hline IAC & $121(14)$ & $0(0)$ & $2(<1)$ & $97(30)$ & $22(26)$ & $0.005^{\mathrm{d}}$ \\
\hline IviC & $27(3)$ & $0(0)$ & $1(<1)$ & $20(6)$ & $6(7)$ & $<0.0001^{\mathrm{e}}$ \\
\hline Enucleation & $279(31)$ & $51(52)$ & $135(34)$ & $68(21)$ & $25(29)$ & 0.35 \\
\hline Treatment refusal & $28(3)$ & $7(7)$ & $9(2)$ & $3(<1)$ & $0(0)$ & $0.03^{f}$ \\
\hline \multicolumn{7}{|l|}{$\begin{array}{l}\text { Outcomes at the end } \\
\text { of the study }\end{array}$} \\
\hline Globe salvage & $513(59)$ & $27(30)$ & $229(58)$ & $197(62)$ & $58(68)$ & $<0.0001 \mathrm{~g}$ \\
\hline HRF & $179(51)$ & $40(63)$ & $75(46)$ & $61(50)$ & $3(11)$ & 0.31 \\
\hline Death & $21(3)$ & $0(0)$ & $16(5)$ & $5(2)$ & $0(0)$ & 0.26 \\
\hline
\end{tabular}

AJCC, American Joint Committee Classification; EBRT, external beam radiotherapy; ${ }^{*}$ Total is more than $100 \%$ since few patients received more than one form of primary treatment; ${ }^{* *}$ argon laser photocoagulation or cryotherapy; IVC, intravenous chemotherapy; IAC, intraarterial chemotherapy; IviC, intravitreal chemotherapy; HRF, high-risk histopathologic features. ${ }^{\text {a }}$ LIC vs. LMIC $(p<0.001)$; LIC vs. UMIC $(p<0.001)$; LIC vs. HIC $(p<0.001)$. ${ }^{\mathrm{b}}$ HIC vs. LMIC $(p=0.003)$; HIC vs. UMIC $(p=0.014)$. ${ }^{\mathrm{c}}$ LIC vs. LMIC $(p=0.011)$; LIC vs. UMIC $(p=0.002)$; LIC vs. HIC $(p<0.001)$; LMIC vs. HIC $(p=0.009) .{ }^{\mathrm{d}}$ LMIC vs. HIC $(p=0.001) .{ }^{\mathrm{e}}$ LMIC vs. UMIC $(p<0.001)$; LMIC vs. HIC $(p<0.001) .{ }^{\mathrm{f}}$ LIC vs. HIC $(p=0.016) .{ }^{\mathrm{g}}$ LIC vs. LMIC $(p<0.001)$; LIC vs. UMIC $(p<0.001)$; LIC vs. HIC $(p<0.001)$.

Table 3. Multivariate linear regression analysis of factors affecting lag time between first symptom and treatment of retinoblastoma in 692 patients from 10 countries.

\begin{tabular}{ccc}
\hline Feature & $p$-Value & Variable Co-Efficient \\
\hline $\begin{array}{c}\text { National income level } \\
\text { Number of visits to primary } \\
\text { healthcare centres before } \\
\text { referral to RB centre } \\
\begin{array}{c}\text { Distance from home to } \\
\text { retinoblastoma centre (miles) } \\
\quad \text { Strabismus as the first } \\
\text { symptom of RB }\end{array}\end{array}<^{\text {Age at diagnosis (months) }}$ & $<0.001$ & $-74.8 \pm 18.3$ \\
\hline
\end{tabular}

After adjusting for the country's income, increased lag time between onset of symptoms and diagnosis of RB was associated with higher chances of an advanced T4 tumour at 
presentation $(p<0.001)$, higher chances of high-risk histopathology features $(p=0.003)$, regional lymph node metastasis $(p<0.001)$, systemic metastasis $(p<0.001)$ and death at time of presentation $(p<0.001)$ (Table 4$)$.

Table 4. Multivariate analysis of marginal linear predictions of factors affected by lag time between first symptom and treatment of retinoblastoma in 692 patients from 10 countries, adjusted for country income level.

\begin{tabular}{ccc}
\hline Feature & $p$-Value & Variable Co-Efficient \\
\hline Tumour category based on 8th edition AJCC & & - \\
T1 * & 0.04 & $-0.0003 \pm 0.00009$ \\
T2 & 0.004 & - \\
T3 & 0.20 & $0.0005 \pm 0.00005$ \\
T4 & $<0.001$ & $0.0003 \pm 0.00001$ \\
\hline Regional lymph node involvement & $<0.001$ & $0.0004 \pm 0.00005$ \\
\hline Metastasis & $<0.001$ & - \\
\hline Primary treatment & & - \\
Focal treatment * & 0.03 & - \\
IVC & 0.54 & - \\
IAC & 0.49 & - \\
IviC & 0.55 & \\
Enucleation & 0.31 & \\
\hline Globe salvage & & $0.0004 \pm 0.0001$ \\
HRF & 0.23 & $0.0002 \pm 0.00004$ \\
Death & 0.003 & $<0.001$ \\
\hline Outcomes at the end of the study &
\end{tabular}

AJCC, American Joint Committee on cancer; T, tumour; IVC, intravenous chemotherapy; IAC, intra-arterial chemotherapy; IviC, intravitreal chemotherapy; HRF, high-risk histopathology features. * $p$-value for the model was not statistically significant at 0.05 .

\section{Discussion}

National income level is an important parameter that may be associated with the patient, family and healthcare professional's education about a disease, accessibility and availability of appropriate care, which may in turn influence the outcomes. There is a significant disparity in the presentation patterns of RB depending on the country's economic grouping. A study of $4351 \mathrm{RB}$ patients from 153 countries from different national income status revealed that patients from LIC had a larger proportion of patients with signs of advanced disease compared to patients from HIC, patients from LIC and LMIC were older at the time of RB diagnosis, and patients from HIC were more commonly associated with intraocular and earlier stage disease while extraocular disease was more common in children from LIC [20]. Similar findings were noted in the present study. Children in LIC were older compared to those in UMIC and HIC at the time of diagnosis of RB; symptoms of advanced disease such as proptosis or fungating mass was more common in LIC compared to HIC; and advanced tumour (cT4) was more common in LIC compared to LMIC or UMIC or HIC.

The disparity in presentation patterns between different countries can affect the outcomes. There is a significant disparity in the outcomes of RB between LMIC/UMIC and HIC. In a global study of 2085 patients from 18 retinoblastoma centres from 13 countries on six continents, including patients from LMIC, UMIC and HIC, it was noted that the metastasis-related mortality rate was 9-10 times higher in children from UMIC/LMIC compared to HIC. The risk of treatment failure (requiring enucleation or external beam radiotherapy) was two-fold higher in children from UMIC and LMIC compared to those from HIC [21]. Enucleation may not always be due to treatment failure but due to nonavailability of other treatment options such as intra-arterial or intra-vitreal chemotherapy in some countries. In our study, which included patients from LIC, LMIC, UMIC and HIC, it was noted that there was an inverse relationship between the risk of metastasis and the 
need for primary/secondary enucleation and the national income status. Patient survival and globe salvage was better in children from HIC compared to those from LIC at the conclusion of this study.

Early diagnosis and treatment of RB results in favourable outcomes with better chances of vision, globe and life salvage. Advanced disease presentation and poor patient outcomes are related to increased lag time before initiation of RB treatment. In our study, there was a significant difference in the lag time between first symptom and initiation of RB treatment for LIC vs. LMIC vs. UMIC vs. HIC. The lag time between first symptom and treatment of RB was 5.4 times higher in LIC, 3.2 times higher in LMIC and 1.6 times higher in UMIC when compared to HIC ( $p=0.0007)$. On multivariate analysis, the factors influencing increased lag time between onset of symptoms and diagnosis of RB included lower-national income level, increased number of visits to primary healthcare centres, increased distance from home to RB treatment centre, strabismus as the first symptom of RB and increasing age. In a comparative study of RB patients from European countries vs. African countries, it was shown that, despite shorter distance of travel for RB care, African patients presented with more advanced disease at presentation compared to those in Europe [22]. The risk factors for advanced disease included lower-national income level and older age and not the distance of travel for care [22]. In our study, although increased distance from home to RB centre was a significant factor in causing increased lag time, lower-national income level was also significant. Increased number of visits to non-RB centres prior to referral to RB centre indicates probable misdiagnosis at non-RB centres resulting in delayed referral to the appropriate RB centre. These early encounters without a diagnosis being made are a missed opportunity to address the problem in a timelier manner. These findings suggest that it is important to increase awareness about RB among parents or family members and general practitioners, to allow early diagnosis and early referral.

The most common symptom of RB in HIC was reported to be leukocoria (56-97\%), while, in LIC, it was proptosis (65\% to $85 \%)$ [11]. Strabismus is the second most common symptom of RB in HIC (24\%) [23], while it is less common in UMIC, LMIC and LIC [11]. In our study, it was noted that, when strabismus was the first symptom of RB, there was an increased lag time before initiation of RB treatment. Whenever strabismus is noted in a child, red reflex testing or fundus evaluation is mandatory to rule out RB and other causes which could result in amblyopia. In our study, increasing age also resulted in increased lag time for RB treatment. This could be related to atypical symptoms of RB such as decreased vision, enlarged eyeball or eyelid swelling, which are more common in older children compared to younger children [24].

Independent of the national income level, ethnicity or socioeconomic status, increased lag time before initiation of RB treatment results in poorer outcomes [10,25]. In our study, when the effect of national income level was adjusted, the consequences of increased lag time between symptoms and diagnosis of RB included advanced tumour at presentation, higher chances of high-risk histopathology features, regional lymph node and systemic metastasis and metastasis-related mortality. Although there was a significant association between increased lag time and high-risk RB in our study, studies from UK [26] and the US [27], have shown that there is no significant association between increased lag time and high-risk histopathology features. This contrasting finding is likely related to the much shorter lag time from first symptom to RB treatment centre in the high-income UK and US groups (median of 31 days in the UK study and 45 days in the US study) compared to this study (median lag time of 69 days, with a median of 251 days and 86 days in LIC and LMIC, respectively).

Based on the results of our study, it is clear that there is a huge disparity in the lag time between different countries resulting in varied outcomes. An effective first step towards decreasing lag time and thereby improving survival in RB within a country is via targeted awareness campaigns. RB education programs could effectively reduce the extraocular disease from $73 \%$ to $35 \%$ within two years in Honduras [28] and from $56 \%$ to $17 \%$ in 
Brazil [29]. Similarly, in the UK, public awareness campaigns have improved the median lag time from eight weeks in the 1990s to five weeks in the 2010s [14,26].

The limitations of the study include unequal distribution of patients across countries and inadequate follow-up period to derive accurate results on final outcomes since this was a prospective short-term study. It is possible that events such as metastasis or death would have occurred after conclusion of the study. In addition, the patients were grouped based on country-income levels, and there is an expected variation in individual family income within each group, which may cause variation of results within the same group.

\section{Materials and Methods}

This study was a collaboration of $11 \mathrm{RB}$ treatment centres located in 10 countries from five continents. The study was approved by the London School of Hygiene \& Tropical Medicine Institutional Review Board (reference No. 15882). All participating centres received clearance from their respective institutional review board and ethics committee for participating in this international collaborative study. The study adhered to the tenets of Declaration of Helsinki. Informed consent was obtained from all parents/guardians of the children included in this study. It was a one-year prospective study that included all treatment-naïve RB patients who presented to the participating centres from 1 January 2019 to 31 December 2019, and who were treated or offered treatment for RB. All patients who had received prior treatment were excluded from this study.

The countries were classified as low-income country (LIC), lower middle-income countries (LMIC), upper middle-income countries (UMIC) or high-income countries (HIC) based on the United Nations World population prospects (2017 revision) [18]. Using a predesigned form, data were collected prospectively as patients presented to the participating centre. The collated data included the patient's country of residence, sex, neonatal history, date of first symptom, visit to primary healthcare professionals, examination at presentation to RB treatment centre, distance from home to the RB centre and primary treatment given (see appendix/supplement for a list of the retrieved parameters). Lag time was defined as the duration between the first symptom (as noticed by parents/family members/others) to treatment of RB at the RB treatment centre. For uniform staging, the 8th edition of the American Joint Committee on Cancer (AJCC) clinical Tumor, Node, Metastasis, Heredity (cTNMH and pTNM) system [19] was used.

\section{Statistical Analysis}

The statistical analysis was performed using R software and STATA v14.2 (StataCorp, College Station, TX, USA). Descriptive measures included mean, median, range and proportion. Data were categorised based on the socioeconomic status of the country; variables were compared by mixed effects model with random intercepts at continent, country and patient levels. Relationships between lag time and other variables were evaluated by multilevel mixed effects linear regression after adjustment for socioeconomic status of the country. A $p$-value of $<0.05$ was considered statistically significant. A Bonferroni correction was used to account for multiple pairwise comparisons among four categories of country based on income. The resulting Bonferroni adjusted alpha level of 0.017 was used, resulting in a $p$-value of $<0.017$ being considered statistically significant.

\section{Conclusions}

This is the first international multi-institutional study to compare the difference in the lag time between symptoms and diagnosis of RB between different countries as well as its influence on the outcomes. There is a huge disparity in the lag time between symptoms and diagnosis of RB among different countries depending on the country's income level. Increased lag time before initiation of RB treatment results in advanced disease at presentation and consequently poorer outcome. While availability and accessibility of healthcare facilities may differ based on national income level, programs focusing on increasing awareness about RB among the care givers and general practitioners would play 
a crucial role in decreasing the lag time and improving patient outcomes. Routine fundus screening of at-risk patients (i.e., with positive family history of RB) or those presenting with strabismus should be encouraged to ensure early diagnosis of RB and minimise lag time.

Author Contributions: Conceptualisation, S.K. and I.D.F.; Methodology, S.K. and I.D.F.; Software, S.K., I.D.F. and A.M.; Validation, S.K., I.D.F. and N.K.-F.; Formal Analysis, D.M.S. and A.M.; Investigation, S.K., X.J., Y.Z., R.R., S.S., S.T.S., N.C., R.Y.D.C., J.L.G.L., A.M.Z.L., V.G.P., T.L.U., S.R.R., A.A., L.A.H., M.A.R., M.S.S., J.L.B., J.K., A.P., N.J.A., C.B., S.B., R.B., M.J.B., A.F., N.G., N.K.-F., S.M., A.W.S., D.M.S., A.M., M.Z. and I.D.F.; Resources, S.K., X.J., Y.Z., R.R., S.S., S.T.S., N.C., R.Y.D.C., J.L.G.L., A.M.Z.L., V.G.P., T.L.U., S.R.R., A.A., L.A.H., M.A.R., M.S.S., J.L.B., J.K., A.P., N.J.A., C.B., S.B., R.B., M.J.B., A.F., N.G., N.K.-F., S.M., A.W.S., D.M.S., A.M., M.Z. and I.D.F.; Writing-Original draft, S.K.; Writing-Review and Editing, S.K., X.J., Y.Z., R.R., S.S., S.T.S., N.C., R.Y.D.C., J.L.G.L., A.M.Z.L., V.G.P., T.L.U., S.R.R., A.A., L.A.H., M.A.R., M.S.S., J.L.B., J.K., A.P., N.J.A., C.B., S.B., R.B., M.J.B., A.F., N.G., N.K.-F., S.M., A.W.S., D.M.S., A.M., M.Z. and I.D.F.; Visualisation, S.K. and I.D.F.; Supervision, S.K., I.D.F. and A.F.; Project Administration, N.J.A., R.B., M.J.B., A.F. and M.Z.; and Funding Acquisition, R.B., M.J.B., A.F. and M.Z. All authors have read and agreed to the published version of the manuscript.

Funding: Support was provided by The Operation Eyesight Universal Institute for Eye Cancer (S.K.) and Hyderabad Eye Research Foundation (S.K., A.M.), Hyderabad, India, and grants from the Wellcome Trust (207472/Z/17/Z) (M.J.B.).

Institutional Review Board Statement: The study was approved by the London School of Hygiene \& Tropical Medicine Institutional Review Board (reference No. 15882). All participating centres received clearance from their respective institutional review board and ethics committee for participating in this international collaborative study. The study adhered to the tenets of Declaration of Helsinki.

Informed Consent Statement: Informed consent was obtained from all parents/guardians of the children included in this study.

Data Availability Statement: The data presented in this study are available on request from the corresponding author. The data are not publicly available due to ethical concerns.

Conflicts of Interest: No conflicting relationship exists for any author.

\section{References}

1. Usmanov, R.H.; Kivelä, T. Predicted trends in the incidence of retinoblastoma in the Asia-Pacific region. Asia Pac. J. Ophthalmol. 2014, 3, 151-157. [CrossRef] [PubMed]

2. Tamboli, A.; Podgor, M.J.; Horm, J.W. The incidence of retinoblastoma in the United States: 1974 through 1985. Arch. Ophthalmol. 1990, 108, 128-132. [CrossRef] [PubMed]

3. Seregard, S.; Lundell, G.; Svedberg, H.; Kivelä, T. Incidence of retinoblastoma from 1958 to 1998 in Northern Europe: Advantages of birth cohort analysis. Ophthalmology 2004, 111, 1228-1232. [CrossRef] [PubMed]

4. MacCarthy, A.; Birch, J.M.; Draper, G.J.; Hungerford, J.L.; Kingston, J.E.; Kroll, M.E.; Onadim, Z.; Stiller, C.A.; Vincent, T.J.; Murphy, M.F. Retinoblastoma in Great Britain 1963-2002. Br. J. Ophthalmol. 2009, 93, 33-37. [CrossRef] [PubMed]

5. Kivelä, T. The epidemiological challenge of the most frequent eye cancer: Retinoblastoma, an issue of birth and death. $\mathrm{Br}$. $J$. Ophthalmol. 2009, 93, 1129-1131. [CrossRef] [PubMed]

6. Steliarova-Foucher, E.; Colombet, M.; Ries, L.A.G.; Moreno, F.; Dolya, A.; Bray, F.; Hesseling, P.; Shin, H.Y.; Stiller, C.A.; IICC-3 contributors. International incidence of childhood cancer, 2001-2010. A population-based registry study. Lancet Oncol. 2017, 18, 719-731. [CrossRef]

7. Stiller, C.A.; Parkin, D.M. Geographic and ethnic variations in the incidence of childhood cancer. Br. Med. Bull. 1996, 52, 682-703. [CrossRef] [PubMed]

8. Howard, S.C.; Metzger, M.L.; Wilimas, J.A.; Quintana, Y.; Pui, C.H.; Robison, L.L.; Ribeiro, R.C. Childhood cancer epidemiology in low-income countries. Cancer 2008, 112, 461-472. [CrossRef]

9. Singh, G.; Daniels, A.B. Disparities in retinoblastoma presentation, treatment, and outcomes in developed and less-developed countries. Semin. Ophthalmol. 2016, 31, 310-316. [CrossRef] [PubMed]

10. Barr, R.D. "Delays" in diagnosis: A misleading concept, yet providing opportunities for advancing clinical care. J. Pediatr. Hematol. Oncol. 2014, 36, 169-172. [CrossRef]

11. Kaliki, S.; Patel, A.; Iram, S.; Ramappa, G.; Mohamed, A.; Palkonda, V.A.R. Retinoblastoma in India: Clinical presentation and outcome in 1457 patients (2074 eyes). Retina 2019, 39, 379-391. [CrossRef]

12. Jain, M.; Rojanaporn, D.; Chawla, B.; Sundar, G.; Gopal, L.; Khetan, V. Retinoblastoma in Asia. Eye 2019, 33, 87-96. [CrossRef] 
13. Kaliki, S.; Shields, C.L.; Eagle, R.C., Jr.; Iram, S.; Shields, J.A. High-risk intraocular retinoblastoma: Comparison between Asian Indians and Americans from two major referral centers. Retina 2018, 38, 2023-2029. [CrossRef] [PubMed]

14. Goddard, A.G.; Kingston, J.E.; Hungerford, J.L. Delay in diagnosis of retinoblastoma: Risk factors and treatment outcome. Br. J. Ophthalmol. 1999, 83, 1320-1323. [CrossRef] [PubMed]

15. Ribeiro Kde, C.; Antoneli, C.B. Trends in eye cancer mortality among children in Brazil, 1980-2002. Pediatr. Blood Cancer 2007, 48, 296-305. [CrossRef]

16. Wallach, M.; Balmer, A.; Munier, F.; Houghton, S.; Pampallona, S.; von der Weid, N.; Beck-Popovic, M.; Swiss Pediatric Oncology Group; Swiss Childhood Cancer Registry. Shorter time to diagnosis and improved stage at presentation in Swiss patients with retinoblastoma treated from 1963 to 2004. Pediatrics 2006, 118, e1493-e1498. [CrossRef] [PubMed]

17. DerKinderen, D.J.; Koten, J.W.; Van Romunde, L.K.; Nagelkerke, N.J.; Tan, K.E.; Beemer, F.A.; Den Otter, W. Early diagnosis of bilateral retinoblastoma reduces death and blindness. Int. J. Cancer 1989, 44, 35-39. [CrossRef] [PubMed]

18. United Nations, Department of Economic and Social Affairs. World Population Prospects: The 2017 Revision. Volume I: Comprehensive Tables; United Nations: New York, NY, USA, 2017; Available online: https:/ / population.un.org/wpp/Publications/Files/WPP2 017_Volume-I_Comprehensive-Tables.pdf (accessed on 15 October 2020).

19. Mallipatna, A.C.; Gallie, B.L.; Chévez-Barrios, P.; Livia, L.R.; Guillermo, L.C.; François, D.; Hervé, J.B.; Francis, L.M.; Daniel, M.A.; Jaume, C.; et al. Retinoblastoma. In AJCC Cancer Staging Manual, 8th ed.; Amin, M.B., Edge, S.B., Greene, F.L., Byrd, D.R., Brookland, R.K., Washington, M.K., Gershenwald, J.E., Compton, C.C., Hess, K.R., Sullivan, D.C., et al., Eds.; Springer: New York, NY, USA, 2017; pp. 819-831.

20. Fabian, I.D.; Abdallah, E.; Abdullahi, S.U.; Abdulqader, R.A.; Adamou Boubacar, S.; Ademola-Popoola, D.S.; Adio, A.; Afshar, A.R.; Aggarwal, P.; Aghaji, A.E.; et al. Global retinoblastoma presentation and analysis by national income level. JAMA Oncol. 2020, 6, 685-695. [PubMed]

21. Tomar, A.S.; Finger, P.T.; Gallie, B.; Kivelä, T.T.; Mallipatna, A.; Zhang, C.; Zhao, J.; Wilson, M.W.; Brenna, R.C.; Burges, M.; et al. Global retinoblastoma treatment outcomes: Association with national income level. Ophthalmology 2020. [CrossRef]

22. Fabian, I.D.; Stacey, A.W.; Foster, A.; Kivelä, T.T.; Munier, F.L.; Keren-Froim, N.; Gomel, N.; Cassoux, N.; Sagoo, M.S.; Reddy, M.A.; et al. Travel burden and clinical presentation of retinoblastoma: Analysis of 1024 patients from 43 African countries and 518 patients from 40 European countries. Br. J. Ophthalmol. 2020. [CrossRef]

23. Abramson, D.H.; Frank, C.M.; Susman, M.; Whalen, M.P.; Dunkel, I.J.; Boyd, N.W., III. Presenting signs of retinoblastoma. J. Pediatr. 1998, 132, 505-508. [CrossRef]

24. Kaliki, S.; Maniar, A.; Patel, A.; Palkonda, V.A.R.; Mohamed, A. Clinical presentation and outcome of retinoblastoma based on age at presentation: A review of 1450 children. Int. Ophthalmol. 2020, 40, 99-107. [CrossRef] [PubMed]

25. Bourkiza, R.; Cumberland, P.; Fabian, I.D.; Abeysekera, H.; Parulekar, M.; Sagoo, M.S.; Rahi, J.; Reddy, M.A. Role of ethnicity and socioeconomic status (SES) in the presentation of retinoblastoma: Findings from the UK. BMJ Open Ophthalmol. 2020, 5, e000415. [CrossRef]

26. Posner, M.; Jaulim, A.; Vasalaki, M.; Rantell, K.; Sagoo, M.S.; Reddy, M.A. Lag time for retinoblastoma in the UK revisited: A retrospective analysis. BMJ Open 2017, 7, e015625. [CrossRef]

27. Butros, L.J.; Abramson, D.H.; Dunkel, I.J. Delayed diagnosis of retinoblastoma: Analysis of degree, cause, and potential consequences. Pediatrics 2002, 109, E45. [CrossRef] [PubMed]

28. Leander, C.; Fu, L.C.; Peña, A.; Howard, S.C.; Rodriguez-Galindo, C.; Wilimas, J.A.; Ribeiro, R.C.; Haik, B. Impact of an education program on late diagnosis of retinoblastoma in Honduras. Pediatr. Blood Cancer 2007, 49, 817-819. [CrossRef]

29. Antoneli, C.B.; Steinhorst, F.; Ribeiro Kde, C.; Chojniak, M.M.; Novaes, P.E.; Arias, V.; Bianchi, A. The pediatrician's ability to recognize the presenting signs and symptoms of retinoblastoma. Rev. Assoc. Med. Bras. 2004, 50, 400-402. [CrossRef] [PubMed] 